\title{
Commentary: del Nido cardioplegia: Can we and do we need to prove the benefit?
}

\author{
Habib Jabagi, MD, MSc, and Munir Boodhwani, MD, MSc, FRCSC
}

\author{
From the Division of Cardiac Surgery, University of Ottawa Heart Institute, Ottawa, Ontario, Canada. \\ Disclosures: Authors have nothing to disclose with regard to commercial support. \\ Received for publication June 3, 2019; accepted for publication June 5, 2019; available ahead of print July 16, \\ 2019 \\ Address for reprints: Munir Boodhwani, MD, MSc, FRCSC, University of Ottawa Heart Institute, 40 Ruskin St, \\ H-34058A, Ottawa, Ontario K1Y 4W7 Canada (E-mail: mboodhwani@ottawaheart.ca). \\ J Thorac Cardiovasc Surg 2020;159:2284-5 \\ $0022-5223 / \$ 36.00$ \\ Copyright (C) 2019 by The American Association for Thoracic Surgery \\ https://doi.org/10.1016/j.jtcvs.2019.06.013
}

Debate on the ideal cardioplegic solution for optimal myocardial protection during adult cardiac surgery has continued since the concept of chemical cardiac arrest was first described by Melrose and colleagues ${ }^{1}$ in the 1950s. Since then, a number of different solutions, with varying compositions, have been developed. Historically, it has been difficult to clearly demonstrate superiority of one over another. ${ }^{2,3}$

Recently, there has been growing interest in the use of single-dose del Nido cardioplegia (DNC) in adults. ${ }^{2,4,5}$ With encouraging in vivo animal data ${ }^{6}$ and demonstrated safe use in pediatric patients, ${ }^{7}$ DNC also provides longer durations of myocardial arrest, ${ }^{6}$ and is believed to reduce myocardial damage through improved preservation of the intracellular milieu. ${ }^{4,8}$ Although comparative studies have demonstrated equivalent clinical outcomes to traditional multidose cardioplegia, these studies remain small and retrospective, with only subtle benefits demonstrated inconsistently. 2,4,5,9

In the recent randomized controlled trial (RCT) by Sanetra and colleagues, ${ }^{10}$ the authors compared the efficacy of single-dose DNC, versus multidose cold blood cardioplegia on myocardial protection in adults undergoing isolated aortic valve replacement. As the second and the largest RCT, their study provides an unbiased comparison of these solutions, and the authors should be congratulated on their extensive assessment of intra- and postoperative outcomes.

Although the inclusion of postoperative biomarkers of myocardial dysfunction and left ventricular echocardiographic assessment were strengths of this RCT, no benefits were observed with DNC. The only improved end point was a lower incidence of ventricular fibrillation after crossclamp; however, this difference did not translate into any meaningful differences in clinically relevant surrogate outcomes, including cardiopulmonary bypass time, postoperative inotrope, and intra-aortic balloon pump use, left ventricular ejection fraction, or major adverse cardiac events. The absence of any difference in a variety of nonclinical, surrogate end points suggests that proving a benefit of one strategy over another with respect to clinical end points will be even more difficult. certain populations.

\section{References} Surg. 1958;96:221-7.

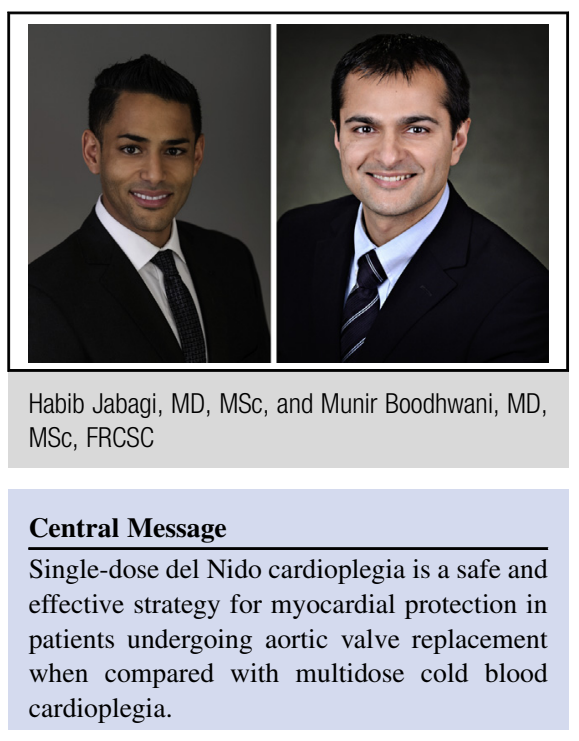

See Article page 2275 .

However, even the lack of difference between the two strategies is an important finding. If one considers both strategies equivalent, this finding allows the surgeon to choose the optimal strategy for their specific patient. For example, the advantage of less frequent redosing may be particularly valuable in cases where cardioplegia delivery is challenging and significantly interrupts the conduct of surgery; for example, minimally invasive procedures or in cases where multiple dose delivery is not feasible such as protection of a donor heart. It is in these populations or in patients with other higher risk and longer ischemic time, rather than a standard aortic valve replacement, where the benefits of DNC may ultimately be realized.

Although the data provided by this study are valuable, Sanetra and colleagues ${ }^{10}$ fail to answer conclusively whether one method of myocardial protection is better than the other. Ultimately, a clinically meaningful difference in myocardial protection strategies remains difficult to prove. However, this may not and need not stop the propagation of $\mathrm{DNC}$ as the preferred method of myocardial protection in

1. Gerbode F, Melrose D. The use of potassium arrest in open cardiac surgery. Am J

2. Mishra P, Jadhav RB, Mohapatra CKR, Khandekar J, Raut C, Ammannaya GK, et al. Comparison of del Nido cardioplegia and St. Thomas Hospital solution- 
two types of cardioplegia in adult cardiac surgery. Kardiochir Torakochirurgia Pol. 2016;13:295-9.

3. Feindel CM, Tait GA, Wilson GJ, Klement P, MacGregor DC. Multidose blood versus crystalloid cardioplegia. Comparison by quantitative assessment of irreversible myocardial injury. J Thorac Cardiovasc Surg. 1984;87:585-95.

4. Nardi P, Pisano C, Bertoldo F, Ruvolo G. New insights on the use of del Nido cardioplegia in the adult cardiac surgery. J Thorac Dis. 2018;10(Suppl 26): $: 3233-6$

5. Kim WK, Kim HR, Kim JB, Jung S-H, Choo SJ, Chung CH, et al. del Nido cardioplegia in adult cardiac surgery: beyond single-valve surgery. Interact Cardiovasc Thorac Surg. 2018;27:81-7.

6. O'Blenes SB, Friesen CH, Ali A, Howlett S. Protecting the aged heart during cardiac surgery: the potential benefits of del Nido cardioplegia. J Thorac Cardiovasc Surg. 2011;141:762-70.
7. Matte GS, del Nido PJ. History and use of del Nido cardioplegia solution at Boston Children's Hospital. J Extra Corpor Technol. 2012;44: 98-103.

8. Yerebakan H, Sorabella RA, Najjar M, Castillero E, Mongero L, Beck J, et al. del Nido cardioplegia can be safely administered in high-risk coronary artery bypass grafting surgery after acute myocardial infarction: a propensity matched comparison. J Cardiothorac Surg. 2014;9:141.

9. Ad N, Holmes SD, Massimiano PS, Rongione AJ, Fornaresio LM, Fitzgerald D The use of del Nido cardioplegia in adult cardiac surgery: a prospective randomized trial. J Thorac Cardiovasc Surg. 2018;155:1011-8.

10. Sanetra K, Gerber W, Shrestha RB, Domaradzki W, Krzych L, Zembala M, et al. The del Nido versus cold blood cardioplegia in aortic valve replacement: a randomized trial. J Thorac Cardiovasc Surg. 2020; 159:2275-83.e1. 